\title{
READERS
Insight
}

Journal of Management Info (JMI)

ISSN:2313-3376

www.readersinsight.net/jmi

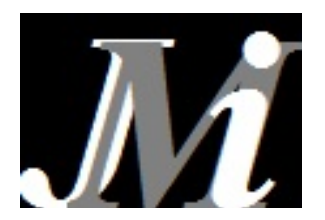

\section{Examining the moderating role of self-monitoring in predicting employees speaking up behavior at workplace}

\author{
Noor Ullah Khan ${ }^{1}$, Muhammad Imran Qureshi2*, Amran Md Rasli \\ ${ }^{1,2}$ COMSATS Institute of Information Technology, Islamabad. \\ ${ }^{3}$ Faculty of Management, Universiti Teknologi Malaysia, 81310 UTM Skudai, Malaysia \\ * Corresponding author: iqmuhammad2@live.utm.my
}

\begin{abstract}
The objective of the present study was to investigate the relationship and moderating effects of selfmonitoring on the relationship between various individual (viz., locus of control and self-esteem) and contextual (viz., top-management openness and trust in supervisor) factors by predicting speaking up behavior of employees at workplace. Sample size of 95 was selected via random probability sampling out of 318 employees from nine management and business institutions or departments of different universities in Peshawar KPK Pakistan. The conclusion drawn from the research study was self-monitoring moderate the relationship between various individual (viz., locus of control and selfesteem) and contextual (viz., top-management openness and trust in supervisor) factors by predicting speaking up behavior in the context of business and management institutions or departments of education universities in Peshawar KPK Pakistan. This research study identifies the possible antecedents that effect the speaking up, which would help to internalize the phenomena of speaking up. This research study would foster the knowledge and understanding of employees about speaking up and would help the organization to adopt better process and programs in order to encourage employees' participation. The future studies may investigate the speaking up with including self-assessment and coworker ratings into study.
\end{abstract}

\section{ARTICLE INFORMATION}

$\begin{array}{ll}\text { Received: } & \text { 25 March2014 } \\ \text { Revised: } & \text { 25 May } 2014 \\ \text { Accepted: } & \text { 25 June } 2014\end{array}$

DOI:

http://dx.doi.org// 10.31580/jmi.v2i1.5

Keywords: Speaking Up, Self-Monitoring, Locus of Control, Self-Esteem, Top Management Openness

\section{Introduction}

Employee input has gained significant recognition as a valuable source of generating ideas to achieve completive advantage (Harrington, 2001). Similarly learning organizations introduce various programmes by involving employees to improve their practices at workplace (Edmondson 1996, 1999). The literature work revealed that management researchers have agreed on the point that employees' contribution or input is significant element in upgrading practices at workplace. In spite many employees are quite hesitant to speak up and prefer to remain silent because of perceived risk of retaliation (Morrison \& Milliken, 2000).

The prior literature about speaking up reported that no specific theory looks quite relevant with speaking up and their conceptual construct which identify the antecedents and procedure to encourage employee's involvement in speaking up. Primarily the current study is based on the research work of Premeaux \& Bedeian(2003). They developed the conceptual scheme and examined the relationship between individual and context related factors and investigated how these variables explain speaking up. Similarly speaking up was predicted by self-monitoring.

The earlier research studies have been provided the justification regarding moderating role of self-monitoring in relationship among different individual and contextual variables while predicting employees speaking up behavior at workplace. The detail discussion has been made in the theoretical background in the comprehensive literature later in the study.
No research study has investigated the moderating role of selfmonitoring in relationship with different individual and context based specifically in the context of business and management institutions or departments in the higher education universities of Peshawar KPK Pakistan.

The prime objective of the current study is to analyze the phenomena where the relationship among individual and context based variables would be moderated by self-monitoring by predicting speaking up among the faculty members business and management institution in Peshawar KPK Pakistan which never been explored.

\section{Scope}

The research study was conducted specifically in the context of business and management institutions or departments including (Institute of Management Science, Peshawar, Islamia College University Peshawar, IBMS Agricultural University Peshawar, IMS University of Peshawar, Abasyn University Peshawar, CECOS University of Information Technology and Emerging Sciences Peshawar, City University of Science and Information Technology Peshawar, Iqra National University Peshawar, Sarhad University of Science and Information Technology Peshawar universities of Peshawar KPK Pakistan. The result of the research can be generalized to the specific context only.

\section{Significance}

This research study pinpoints the possible antecedents that effect the speaking up behavior of employees, which would help to 
internalize the phenomena of speaking up inside organization. Secondly this research study would foster the knowhow of employees about speaking up and would help the organization to adopt better process and programs in order to encourage employee's participation. The result of this research study would facilitate the management to address the individual and context based variable which encourage the employees to speak up.

\section{Literature review}

Speaking up can be defined as "Speaking up refers to voluntary efforts to raise an issue or concern to those in positions of higher authority". The prior literature linked the term speaking up with various relevant theoretical constructs like voice, issue-selling, dissent, whistle-blowing, taking charge, breaking silence, and helpseeking (Ashford et al. 1998).

\section{Impediments to speaking up}

Most of the time employees can't speak up about workplace happenings because they feel the risk of possible personal cost (Detert and Treviño 2010, Kish Gephart et al. 2009, Milliken, Morrison, and Hewlin 2003, Morrison and Milliken 2000, Tangirala and Ramanujam 2008a, Van Dyne, Ang, and Botero 2003). Self-protection, resignation, absence of other-orientation discourages the speaking up behavior (Van Dyne et al. 2003).

The perceived interpersonal risk discourages the employees speaking up behavior (Edmondson 1996, 1999). So many employees remain silent because of potential issues they may would adversely affect their career, promotions and raises. Apart from these fears employees don't want to invest their energies and time to speak up at workplace. Because they are not sure about the consequences of expressing their ideas and opinions regarding workplace happening (Blatt et al. 2006, Tucker and Edmondson 2003, Tucker 2007). Employees are not well convinced to challenge the status quo for their own coworkers as well as organization. (Van Dyne et al. 2003).

\section{Encouraging speaking up}

The prior research studies have investigated many management practices to mitigate the perceived hurdles about speaking up behavior, like to behave in a way out to mitigate the perceived fears of status quo and power of employees in order to create an atmosphere which is psychologically secure (Detert and Burris 2007, Edmondson 1999, 2003, Nembhard and Edmondson 2006.Creating psychologically safe workplace can reduce perceived risk of hesitation to discuss and report mistake (Edmondson 1996). Similarly the managers can encourage the speaking up by addressing the issues in supportive and cooperative manner which would ultimately motivate the employees to share their ideas (Ashford 1998, Detert and Burris 2007, Dutton and Ashford 1993, Morrison and Phelps 1999, Tangirala and Ramanujam 2008a, Tucker 2007). Managers can introduce a better mechanism to reward their employees in order to encourage speaking up, (Nembhard and Edmondson 2006). These prior studies have been investigated how managers can promote and faster speaking up behavior.

\section{Speaking up}

The past literature encompasses various monological networks to lessen the barriers by breaking the "wall of silence" because of which employees are willing to speak up regarding workplace happenings. Speaking up refers "as openly stating one's views or opinions about workplace matters, including the actions or ideas of others, suggested or needed changes, and alternative approaches or different lines of reasoning for addressing job-related issues" (Premeaux,\&Bedeian, 2003).

This study uses the speaking up conceptually in different way as compared to other terms used for employee's expressions at workplace. Like the term speaking up is relevant but different from dissent in organization. Speaking up can be viewed in positive context in order to promote and advance organizational practices on different and unique grounds. Speaking up is only concern with employees oriented expressions. The speaking up in the current study shares some grounds of similarity with conceptualization of voice behavior by (Van Dyne et al.'s (1995) which highlighted to foster procedural and administrative grounds to bring improvements in organization not to criticize the status quo at workplace. The speaking up encompasses not just employee oriented expression but also addresses other grounds of actions and opinions or issues related to employee's job. The prior research findings explored that management scholars and practitioners have never been developed mutual consensus to define voice which is acceptable universally. Since last almost past 30 years the monological network of voice and their operational definitions had been varied broadly (e.g., Avery and Quiñones, 2002). The above discussion about various constructs pinpointed the difference between speaking up and other terms used for employee's voice. In nutshell the purpose of the discussion was to get a clear understanding of the term speaking up rather confusing it with other related constructs.

\section{Theoretical background}

The prior literature about speaking up has been revealed that no theory looks quite relevant with speaking up and their monological network which can possibly figure out the antecedents and mechanism to foster employee's tendency towards speaking up. Primarily the current study is based on the research work of Premeaux $\&$ Bedeian in (2003). They developed the conceptual scheme on the basis of past literature and examined that relationship between different individual and context based variables will be moderated by of self-monitoring in order to predict speaking up. Likewise selfmonitoring is a significant predictor of employees speaking up behavior. The earlier research studies have been provided the justification regarding moderating role of self-monitoring in relationship among different individual and contextual variables while predicting employees speaking up behavior at workplace.

The first justification is about there are various contexts where individual foster and monitor their own self-image and appearances by keeping the interpersonal relationship intact at workplace setting (Gangestad and Snyder, 2000).

Secondly the prior research studies have been justified the evidence that individuals monitor their representative self-image according to the desired manifestation public at workplace which provides a basis for internalizing the different elements of interpersonal dynamics (including speaking up). Similarly self-monitoring can predict individual's stance about social networking at workplace. Because including both low and high self-monitors are willingly putting efforts to construct their social worldview at workplace (Mehra et al., 2001). Finally the earlier research findings have been revealed that management and organizational researchers developed mutual consensus that self-monitoring does play a significant contribution in nurturing employee behavior. The research findings showed that high self-monitors have greater ability to become a leader rather than low self- monitors (e.g., Day et al., 2002).

In nutshell self-monitoring has significant influence over individual behavioral preferences at social and interpersonal relationship fronts. Research studies revealed that self-monitoring associate individual thought with their actions which ultimately help to investigate the self-regulatory practices (Tiedens, 2001).

The past research studies have provided supportive stance for conceptual framework of this study where both individual and contextual variables influence the employees intent to participated in speak up.

Discretionary behavior had been gained significant attention from research scholars in the past. Both individual and contextual are important factors in predicting human interactions. Both affect the individual behavior to greater extent. Various research studies suggested that both individual variables have association with speaking up (Ashford et al. 1998).

The past research study suggested that Top management openness (TMO) has significantly associated with employees speaking up at workplace. TMO refers to the level where top management promotes employees contribution in terms of ideas opinions which plays a significant part in making the context favorable. The other contextual 
variable is trust in supervisor which also has greater association with employees speaking up. Increased contribution of both variables encourage speaking up at workplace (Premeaux, S. F \&Bedeian, A. G, 2003).

\section{Self-monitoring}

Self-monitoring is basically concern with how individual monitor, differ and modify their display of self-presentation at various contexts at workplace settings. The impression management has significant relationship with self-monitoring. Accordingly Snyder defined selfmonitoring that "the processes of self-monitoring are, quite literally, those that link thought to action"(p . 111).High self-monitors (HSMs) have the ability to modify their behavior according to requirements of the context. On other hand low self-monitors (LSMs) lack the ability to alter their behavior according to situation (Snyder, 1979).

High self-minters (HSM) possess proactive nature to modify and regulate self-image in various context. HSM has the characteristics to read the context and audience and play their role according to desired settings. Unlikely low self-monitors (LSMs) lack the characteristics to modify and adjust their behavior rather HSMs express their true inner self irrespective of situational demands. HSMs have no interest to show the false self-image at various contextual settings ( Gangestad and Snyder, 2000).

Low self-monitors (LSMs) have no interest to display false self-image rather welling to expose their true self at situational context with using the logic that they want allow their authentic self. In nutshell based on the above discussion about self-monitoring HSMs is related with speaking up and how it influences the self-image of individuals in situational context. On other side LSMs are less associated with how to modify self-image and to display fake self-image rather than real self but more related with speaking up (Gangestad and Snyder, 2000). The variations in the characteristics of HSMs and LSMs would play the moderation role in predicting speaking up with various individuals and contextual variables.

\section{Locus of control}

The internal locus of control (LOC) is basically concern when individual believe that he is responsible for events happenings in their lives. Individual with internal dimension strongly believes that their lives are not dominated by fate or other external factors. The individual with external locus of control (LOC) believe that other factors like fate, chance and power strongly determined their lives. They blame external factors for their success and failure where the individual with internal dimension believe in proactive approaches of planning, coping etc (Rotter, 1992).

The prior studies revealed that as compared to externals individuals with internal dimension showed positive relationship with selfefficacy (Phillips and Gully, 1997). Internal because of proactive approaches can perform better than externals at specific contexts (Kren, 1992). The internal has reported significant relationship with job happening at workplace (Mitchell et al., 1975).

The past literature has reported that individual with internal locus of control showed greater tendency to speaking up where external are not interested to speak up. Self-monitoring in interaction with locus of control create a relatively complex understanding where the HSM s are interested to modify their real self-image and LSMs showed less tendency to promote the fake image of their self (Snyder, 1979).

Comparatively internal required HSMs to modify their self-image. Internal in interaction with LSMs would participate more in speaking up rather than external with HSMs (Gangestad\& Snyder, 2000; Premeaux \& Bedeian, 2003).

H1: The interaction between locus of control and speaking up will be moderated by self-monitoring.

\section{Self-esteem}

Self-esteem refers basically involves self-evaluation based on context favorability and a significant element in predicting individual behavior (LePine and Van Dyne). Research findings reported that self-esteem has positively related with individual explicit behavior. Individual with low self-esteem will speak up high. Self-esteem is concern with measuring individual beliefs and style based on selfpresentation. A positive relationship was reported between organizational change and self-esteem (Judge et al., 1999).

Research findings reported that individuals having rated low on selfesteem try to protect themselves and at times they do speak. But normally individuals with high self-esteem are often avoiding speaking up and they don't show much tendency to speak up. Individuals having low self-esteem usually looking for recognition of others by using self-presentational approaches In the context of selfmonitoring the Individuals who ranked low on self-esteem uses HSMs to promote and modify their self-image. In contrast to this individual with high self-esteem don't use the HSMs to modify their self-image (Mehra et al., 2001).

Previous research study in the context of self-monitoring, high selfesteem in interaction with LSMs the individuals are supposed to speak up more. The justification to this is based on the rational that normally LSMs are not inclined to modify their true self-image where HSMs are more inclined to modify and project their fake self-image (Gangestad and Snyder, 2000). LSMs are driven by their inner beliefs in contrast HSMs are consistently influenced by reading the context to display their self-image (Jawahar, 2001).

H2: the association between self-esteem and speaking up will be moderated by self-monitoring.

\section{Top management openness}

Top management openness (TMO) refers to the extent of encouraging employees to express their ideas and suggestions by top management. TMO is a significant predictor for employees to make decision regarding their stance on issue with top management. The Ashford and her colleagues (1998) reported that the positive perception of employees about top management would encourage and increase their proactive efforts at workplace.

The previous studies supported the finding have reported that TMO has positive relationship with taking charge and innovative behavior of employees (Morrison \& Phelps, 1999 Scott and Bruce, 1994). The past research study revealed that usually subordinates make attempts to influence their top managers (Schilit\& Locke, 1982).

Top management encouragement for employees is quite relative in the context of self-monitoring. LSMs would like to participate in speaking up more as compared to HSMs who often read the context before expressing their ideas to top management (Premeaux \&Bedeian, 2003).

HSMs usually read the context to make a modify image of their true self because individuals with HSMs believed that they can manipulate the context and to display image which demands by the situations. They are welling get align with top management to get their own goals by reading the situation (Gangestad and Snyder, 2000).

In contrast to the discussion on other side LSMs usually perceive that they are not in a position to read the context because they believe in true inner self rather than believing fake self for the sake of situational demands (Fandt and Ferris, 1990).

The assumption that HSMs are less inclined to participate in speaking up rather than LSMs individuals show greater tendency to speak up got supportive grounds from Arkin's theory. The theory basically explains the self-presentation mechanism of individual and how individual modify their behavior.

Therefore based on above discussion accordingly individuals modify and alter their self-image for demands of social context and public concerns which would possibly enhance speaking up of LSMs in interaction with top management openness.

H3: the relation between TMO and speaking up will be moderated by self-monitoring.

\section{Trust in supervisor}

Trust basically refers to "involving confident positive expectations about another's motive with respect to oneself in situations entailing risk" (Boon and Holmes, 1991, p. 194). Trust is vital factor in all nature of relationships at workplace (e.g. McAllister, 1995). 
Trust in supervisor is a significant contextual variable in predicting individual values at workplace (Brockner et al., 1997). The supervisory power influences the outcomes of employees. The trust in supervisor is important element in employee's decision regarding speaking up at workplace (Pierce et al., 1984).

The previous research findings reported that the trust in supervisor and speaking up relationship influenced by the moderating nature of self-monitoring. The LSMs and high trust in supervisor would enhance speaking up because LSMs are to relatively speak more as compared to HSMs without reading the clue in the context (Snyder and Gangestad, 2000).

On other hand HSMs are more willing to read the context and to manipulate the opportunities more politically in order to react in way which required out there.HSMs usually read the context to make a modify image of their true self because individuals with HSMs believed that they can manipulate the context and to display image which demands by the situations (Snyder and Gangestad, 2000).

Moreover, based on the above discussion in interaction with TMO and predicting speaking up to for promoting a real self-image HSMs relatively participating less in speaking up as compared to LSMs who speak up more without reading the clues in the context.

H4: the relation between trust in supervisor and speaking up will be moderated by self-monitoring.

\section{Theoretical framework}

The framework of this research study pinpointed the conceptual scheme shown in the figure 1, below that explains the phenomena of employees speaking up at workplace. Further the framework proposes that the relationship between different individual and context related variables will be moderated by self-monitoring in predicting speaking up. Due to limited scope the current research study uses the term conceptual scheme.

\section{Research study variables}

The variables included as independent are Locus of control, selfesteem, TMO and trust in supervisor while Speaking up is dependent and Self-monitoring is moderating variable

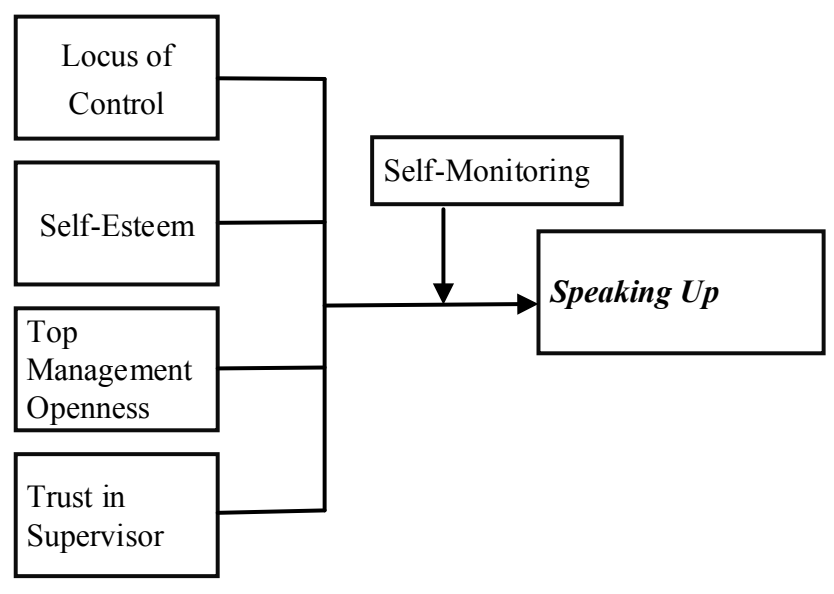

Fig1. Schematic diagram

\section{Methodology}

The sample of 95 was selected via random probability sampling out of 318 employees from nine management and business institutions or departments of different universities in Peshawar KPK Pakistan. Primarily the current study is based on the research work of (Premeaux \&Bedeian, 2003). They made a conceptual construct base on the relationship between individual and context related factors speaking up.

This segment of education industry was selected because, it was more appropriate for the research study. Firstly management and business education has experienced a significant growth since last few years. This part of education industry (business \&management institutions) went through phenomenal changes. Secondly management and business education industry has well-equipped with both atmospheres, where speaking up (specially expressing ideas and opinions regarding job and other issues) are highly valued. However at times employees input have been ignored by the management in certain cases. The confidentiality of data was assured and the participants were told that the data would be used only for research purpose.

The data was collected via standard questionnaires. The questionnaires were administered personally among the faculty remembers of business and management institutions in Peshawar.

The sample size consisted of employees of different status and designation. The descriptive statistics analysis was used to find the averages, frequencies and cumulative percentages of variables like age, gender, qualification, designation and status of the respondents. The dependent, independent and moderating variables were tested statistically via moderated multiple regressions after exporting their corresponding average scores into SPPS 16 version.

\section{Survey instruments \\ Top management openness}

Top management is primarily concern with measuring the extent of encouraging employees input by upper management. The TMO was measurement was done by six items scale made by (Ashford, 1998). All the questions were rated in five item scale $(1=$ strongly disagree to $5=$ strongly agree 1 ).

\section{Trust-in-supervisor}

This variable was measured with four items scale developed by (Read's 1962). The sample question included. All the questions were rated in five item scale $(1=$ strongly disagree to $5=$ strongly agree 1$)$. This instrument is quite consistent with past research studies (Hopwood, 1972; Otley, 1978; Ross, 1994; Lau and Buckland, 2001; Lau and Sholihin, 2005; Lau and Tan, 2006).

\section{Locus of control}

The locus of control was measured with eight items scale on internality dimension developed by Levenson's (1974. The sample question included. All the questions were rated in five item scale $(1=$ strongly disagree to $5=$ strongly agree 1 ).

\section{Speaking up}

Speaking up refers "how employees presents their ideas and opinions. Speaking up was measured by six items scale developed by (Premeaux \& Bedeian, 2003). The sample question included "Speaks up when workplace happenings conflict with his/her sense of what is appropriate". All the questions were rated in five item scale (1= strongly disagree to $5=$ strongly agree 1 ).

\section{Self - monitoring}

Self-monitoring refers to "the ability of modify self-presentation and sensitivity to the expressive behavior of other" (Lennox and Wolfe 1984). Self-monitoring was measured by thirteen items scale developed by (Lennox and Wolfe 1984). The sample question included "In social situations I have the ability to alter my behavior if I feel that something else called for". All the questions were rated in five item scale $(1=$ strongly disagree to $5=$ strongly).

\section{Self esteem}

The self-esteem was measured by ten items developed by (Rosenberg, 1965). The sample question included "on the one whole I am satisfied with myself'. All the questions were rated in five item scale $(1=$ strongly disagree to $5=$ strongly $)$.

\section{Analysis and results}

This research study primarily investigated the linear relationship , level of significance and the moderation effects of self-monitoring on various between various individual (viz., locus of control and self- 
esteem) and contextual (viz., top-management openness and trust in supervisor) variables in predicting speaking up. The analysis of this study consisted of four parts which includes descriptive statistics analysis, correlation analysis, linear and multiple regression analysis and moderation analysis.

\section{Correlation analysis}

Table 2.1: Correlation Analysis

\begin{tabular}{lllllll}
\hline \multicolumn{2}{c}{ SM } & LC & SE & TMO & TS & SUP \\
\hline SM & 1 & & & & & \\
LC & -.179 & 1 & & & & \\
SE & $.676^{* *}$ & .166 & 1 & & & \\
TMO & $-.406^{* *}$ & .103 & $-.436^{* *}$ & 1 & & \\
TS & $-.478^{* *}$ & .106 & $-.485^{* *}$ & $.793^{* *}$ & 1 & \\
SUP & $-.601^{* *}$ & $.428^{* *}$ & $-.508^{* *}$ & $.565^{* *}$ & $.587^{* *}$ & 1 \\
\hline$* *$ Correlation
\end{tabular}

**Correlation is significant at .01 level (2-tailed)

$\mathrm{SM}=$ Self-monitoring, $\mathrm{LC}=$ Locus of control, $\mathrm{SE}=$ Self esteem, $\mathrm{TMO}=\mathrm{Top}$ manaement openness, $\mathrm{TS}=$ Trust in supervisor, $\mathrm{SUP}=$ Speaking up

\section{Correlation and results}

This second part of analysis was comprised of correlation analysis. Correlation analysis has confirmed the existence of linear relationship or association between the impendent, moderating and dependent variables. The correlation analysis supported the first part of the suggested hypothesis which was important to for the qualification of independent variables to be used in moderation analysis later. Table 2.1 describes the correlation score.

The results have confirmed that self-monitoring was related negatively with speaking up, the value of coefficient of correlation $(\mathrm{r}=-.601)$. The internal dimension of locus of control was related positively with speaking up, with value of $(\mathrm{r}=.428)$. The results were confirmed negative relationship with speaking up where the value of $(\mathrm{r}=-.508)$. The top management openness was associated positively with speaking up having the value of $(\mathrm{r}=.565)$. The results revealed the positive association of trust in supervisor with speaking up having the value of $(\mathrm{r}=.587)$.

\section{Multiple regressions}

Table 3.1: Overall Model Summary

\begin{tabular}{lllll}
\multicolumn{3}{l}{ Table 3.1: Overall Model Summary } \\
\hline Model & $\mathbf{R}$ & $\mathbf{R}$ square & $\begin{array}{l}\text { Adjusted } \\
\text { R Square }\end{array}$ & $\begin{array}{l}\text { Std. Error of } \\
\text { the Estimate }\end{array}$ \\
\hline 1 & $.796^{\mathrm{a}}$ & .634 & .614 & .38197 \\
\hline Predictors:(constant),TS,LC,SM,TMO
\end{tabular}

Table 3.2: ANOVA

\begin{tabular}{llllll}
\multicolumn{1}{l}{ Table 3.2: ANOVA } & & & Sig. \\
\hline Model & $\begin{array}{l}\text { Sum of } \\
\text { Squares }\end{array}$ & df & $\begin{array}{l}\text { Mean } \\
\text { Square }\end{array}$ & F & \\
\hline Regression & 22.509 & 5 & 4.502 & 30.855 & $.000^{\mathrm{a}}$ \\
Residual & 12.986 & 89 & .146 & & \\
Total & 35.495 & 94 & & & \\
\hline Dependent variable: Speaking up & &
\end{tabular}

The third part of analysis comprised of inferential statistics. The first sub part multiple regression model reported that the overall model is highly significant. The table 3.2 presented the values of $\mathrm{R}$ square, $\mathrm{F}$ statistics, and significance of model. The all independent variable including moderating variable explained the speaking up to greater extent. The statistics confirmed that significance value (F (30.855) $=30.00,(\mathrm{p}<0.05)$ the coefficient of determination value was $(\mathrm{R}$ square $=.614$ )means all the variables shows variability of almost $61 \%$ for the dependent variable speaking up at $95 \%$ probability level.

\section{Linear regression analysis}

The second sub part of analysis consisted of linear regression. The table 3.3 presented the results. The statistics have confirmed that individually all the variables were significantly explained the speaking up.The moderating variable self-monitoring explained the speaking up 35\% at significance level $(\mathrm{F}(52.525)=52.00,(\mathrm{p}<0.05)$ (adjusted R square $=.354$ ) at $95 \%$ probability level.

\begin{tabular}{lllllll}
\multicolumn{6}{l}{ Table 3.3: Individual Models Summary } \\
\hline Var & $\mathbf{R}$ & $\begin{array}{l}\mathbf{R} \\
\text { Square }\end{array}$ & $\begin{array}{l}\text { Adjusted } \\
\mathbf{R} \\
\text { Square }\end{array}$ & $\begin{array}{l}\text { Std. Error } \\
\text { of the } \\
\text { Estimate }\end{array}$ & $\mathbf{F}$ & Sig. \\
\hline SUP & -- & -- & -- & -- & -- & -- \\
SM & $.601^{\mathrm{a}}$ & .361 & .354 & .49387 & 52.525 & $.000^{\mathrm{a}}$ \\
LC & $.428^{\mathrm{a}}$ & .183 & .174 & .55832 & 20.869 & $.000^{\mathrm{a}}$ \\
SE & $.508^{\mathrm{a}}$ & .258 & .250 & .53219 & 32.323 & $.000^{\mathrm{a}}$ \\
TMO & $.565^{\mathrm{a}}$ & .319 & .312 & .50973 & 43.609 & $.000^{\mathrm{a}}$ \\
TS & $.587^{\mathrm{a}}$ & .344 & & .50029 & 48.85 & $.000^{\mathrm{a}}$ \\
\hline
\end{tabular}

Note: * $p<0.05$

$\mathrm{SM}=$ Self-monitoring, $\mathrm{LC}=\mathrm{L}$ ocus of control, $\mathrm{SE}=\mathrm{Self}$ esteem, TMO=Top manaement openness, TS=Trust in supervisor, SUP=Speaking up

The independent variables locus of control explained $17 \%$ the dependent variable speaking up at significance level $(\mathrm{F}(20.869)=$ 20.00, $(\mathrm{p}<0.05)$ (adjusted R square $=.174)$ at $95 \%$ probability level. The self-esteem explained $25 \%$ speaking up where significance level $(\mathrm{F}(32.323)=32.00,(\mathrm{p}<0.05)($ adjusted $\mathrm{R}$ square $=.250)$ at $95 \%$ probability level. The top management openness showed variability of $31 \%$ with significance level $(\mathrm{F}(43.609)=43.00,(\mathrm{p}<0.05)$ (adjusted $\mathrm{R}$ square $=.312$ ) at $95 \%$ probability level. The trust in supervisor explained the speaking up by $37 \%$ with level of significance ( $\mathrm{F}$ $(48.850)=48.00,(\mathrm{p}<0.05)$ (adjusted $\mathrm{R}$ square $=.377)$ at $95 \%$ probability level.

\section{Moderation analysis}

Table 4.1: Moderation Analysis

\begin{tabular}{|c|c|c|c|c|c|c|}
\hline Variables & $\mathbf{R}$ & $\begin{array}{l}\mathbf{R} \\
\text { Square }\end{array}$ & $\begin{array}{l}\text { Adjusted } \\
\mathbf{R} \\
\text { Square }\end{array}$ & $\begin{array}{l}\text { Std. } \\
\text { Error of } \\
\text { the } \\
\text { Estimate }\end{array}$ & $F$ & Sig. \\
\hline \multicolumn{7}{|l|}{ SUP } \\
\hline LC & $.428^{a}$ & .183 & .174 & .55832 & 20.869 & $.000^{\circ}$ \\
\hline $\begin{array}{l}\text { LOC with } \\
\text { interaction } \\
\text { term }\end{array}$ & $.474^{a}$ & .225 & .208 & .54684 & 13.349 & $.000^{\circ}$ \\
\hline $\mathrm{SE}$ & $.508^{a}$ & .258 & .250 & .53219 & 32.323 & $.000^{\circ}$ \\
\hline $\begin{array}{l}\text { SE with } \\
\text { interaction } \\
\text { term }\end{array}$ & $.519^{a}$ & .269 & .247 & .53320 & 16.423 & $.000^{\circ}$ \\
\hline TMO & $.565^{a}$ & .319 & .312 & .50973 & 43.609 & $.000^{\circ}$ \\
\hline $\begin{array}{l}\text { TMO with } \\
\text { interaction } \\
\text { term }\end{array}$ & $.589^{a}$ & .347 & .333 & .50188 & 24.455 & $.000^{\circ}$ \\
\hline TS & $.587^{a}$ & .344 & .377 & .50029 & 48.850 & $.000^{\circ}$ \\
\hline $\begin{array}{l}\text { TS with } \\
\text { interaction } \\
\text { term }\end{array}$ & $.591^{\mathrm{a}}$ & .349 & .388 & .50124 & 24.638 & $.000^{\circ}$ \\
\hline
\end{tabular}

The forth part of inferential statistics comprised of moderated multiple regressions. This part of the analysis was tested the suggested hypothesis which includes the use of interaction term. The above table 4.1 represented the comprehensive results of moderation analysis. The increased values of $\mathrm{R}$ square because of interaction term were highlighted bold in the shaded rows. The model of moderated regression was significant.

H1: The statistics showed that relationship has been strengthened between the locus of control and self-monitoring the value of (coefficient of correlation increased from $\mathrm{r}=.428$ to .474 ) where the variability of $\mathrm{R}$ square also showed improvement from (.183 to.225) means first locus of control was explaining speaking up $18 \%$ and after moderation the value increased up to $22 \%$ at probability level $(\mathrm{p}<.05)$ so results were supported hypothesis 1.

H2: The statistics confirmed this verification where the value of the value of (coefficient of correlation slightly increased from $\mathrm{r}=.508$ to $.519) \mathrm{R}$ square increased form (R square .258 to .269) which shows almost $1 \%$ increase in the value at probability level $(\mathrm{p}<.05)$. So results were supported hypothesis 2 . 
H3: the moderation results revealed that moderation exist between top management openness and speaking up which interaction term of selfmonitoring was included in the moderated regression. The increase in the value of $\mathrm{r}$ and $\mathrm{R}$ square showed the effects of moderation. The value of (coefficient of correlation slightly increased from $r=.565$ to .589) $\mathrm{R}$ square increased form ( $\mathrm{R}$ square .319 to .347) which increased the predictability value from $31 \%$ to $34 \%$ at probability level $(\mathrm{p}<.05)$. So results were supported hypothesis 3 .

H4: the moderated regression provides supportive stance to the last hypothesis that relationship between trust in supervisor and speaking up moderated by self-monitoring low. The values of $r$ and $R$ square showed slight improvements. The value of (coefficient of correlation slightly increased from $\mathrm{r}=.589$ to .591$) \mathrm{R}$ square increased form ( $\mathrm{R}$ square .344 to .349$)$ at probability level $(\mathrm{p}<.05)$. So results were supported hypothesis 4 partially.

\section{Discussion and findings}

\section{Individual factors}

The first part of results reported that both individual factors predict speaking up significantly when interacted with selfmoderating variable self-monitoring. Individually locus of control predicted speaking up in interaction with self-monitoring. The statistics showed that relationship has been strengthened between both variables with speaking up when self-monitoring used as interaction term to the analysis. The findings of this research study were similar to the previous study where similar finding was given by (Premeaux \&Bedeian, 2003).

\section{Contextual factors}

The second part of the findings confirmed that both contextual factor i-e top management openness and trust in supervisor were explained speaking up significantly when interaction terms of self monitoring was used in the moderation analysis. Self monitoring moderated significantly the relationship among top management and speaking up. The findings of this research study were similar to the Arkin theory (1981) which explained individual uses self monitoring as tool to regulate their self image according to the situation demands. The findings were supported by the other study by Gangestad \& Snyder's (2000).

Similarly the last contextual factor trust is supervisor explained the speaking up significantly when self monitoring was interacted with trust in supervisor in moderated regression. But in this case similar to self esteem the moderation effect was low. This part of the results was aligned with the finding revealed by (Snyder \&Gangestad, 1982).

In nutshell based on the above discussion about self monitoring HSMs is related with speaking up it influences the self image of individuals in situational context. On other side LSMs are less associated with how to modify self image and to display fake self image rather than real self but more related with speaking up. The variations in the characteristics of HSMs and LSMs played the moderation role in predicting speaking up with various individuals and contextual variables (Gangestad\& Snyder, 2000).

\section{Practical implications}

This research study identifies the possible antecedents that effect the speaking up, which would help to internalize the phenomena of speaking up. This research study would foster the know how of employees about speaking up and would help the organization to adopt better process and programs in order to encourage employees participation. The result of this research study would facilitate the management to address the individual and contextual, factors which encourage the employees speak up

\section{Future research directions}

This research study couldn't able to explain unfold nature of speaking up with time. So future study is needed to explore this unfold nature of speaking up with time. The future studies may investigate the speaking up with including self assessment and coworker ratings into study. The future research should take bigger sample size and employees with different academics and in different industries.

\section{Limitations}

This research study based on cross-sectional analyses, at times cross-sectional or Prevalence studies can't produce true test for causality. The generalizability of results could be limited by relatively small sample size.

\section{Conclusion}

A cross-sectional study research study has investigated that self monitoring moderate the relationship individual variables to predict specifically in the context of business and management institutions or departments of education universities in Peshawar KPK Pakistan. In brief based on the findings of this study both individual (viz., locus of control and self-esteem) and contextual (viz., top-management openness and trust in supervisor) factors explained the speaking up significantly when interacted with interaction term of self monitoring. This research study figure out the possible antecedents that effect the speaking up, would enhance the knowledge of employees and organization about speaking up to adopt better process and programs in order to encourage employees participation. The cross-sectional study which is limited by relatively small sample size the results can be generalized to the included intuitions. The future studies may investigate the speaking up including self assessment and coworker ratings with bigger sample size and employees with different academics levels.

\section{References}

Ashford, S. J., Rothbard, N. P., Piderit, S. K. and Dutton, J. W. (1998). 'Out on a limb: the role of context and impression management in selling gender-equity issues'. Administrative Science Quarterly, 43, 23-57.

Avery, D. R. and Quiñones, M. A. (2002). 'Disentangling the effects of voice: the incremental roles of opportunity, behavior, and instrumentality in predicting procedural fairness'. Journal of Applied Psychology, 87, 81-6.

Baumeister, R. F., Tice, D. M. and Hutton, D. G. (1989). 'Self-presentational motivations and personality differences in self-esteem'. Journal of Personality, 57, 547-79.

Blatt, R., M. K. Christianson, K. M. Sutcliffe, M. M. Rosenthal. 2006. A sensemaking lens on reliability. Journal of Organizational Behavior 27(7): 897-917.

Brockner, J., Siegel, P. A., Daly, J. P., Tyler, T. and Martin, C. (1997). 'When trust matters: the moderating effect of outcome favorability'. Administration Science Quarierly, 42, 558-83.

Day, D. V., Schleicher, D. J., Unckless, A. L. and Hiller, N. J. (2002). 'Selfmonitoring personality at work: a meta-analysis'. Journal of Applied Psychology, 87, 390-401.

Fandt, P. M. and Ferris, G. R. (1990). 'The management of information and impressions: when employees behave opportunistically'. Organizational Behavior and Human Decision Processes, 45, 140-58.

Gangestad, S. W. and Snyder, M. (2000). 'Self-monitoring: appraisal and reappraisal'. Psychological Bulletin, 126, 530-55.

Graham, J. W. (1986). 'Principled organizational dissent: a theoretical essay'. Research in Organizational Behavior, 8, 1-52.

Harrington, B. E. (2001). 'Organizational performance and corporate social capital: a contingency model'. Research in the Sociology of Organizations, 18, 83-106.

Jawahar, I. M. (2001). 'Attitudes, self-monitoring, and appraisal behaviors'. Journal of Applied Psychology, 86, 875-83.

Judge, T. A., Thoresen, C. J., Pucik, V. and Welbourne, T. M. (1999). 'Managerial coping with organizational change: a dispositional perspective'. Journal of Applied Psychology, 84, 107-22.

Kren, L. (1992). 'The moderating effects of locus of control on performance incentives and participation'. Human Relations, 45, 991-1012.

Lennox, R. D. and Wolfe, R. N. (1984). 'Revision of the self-monitoring scale'. Journal of Personality and Social Psychology, 46, 1349-64.

LePine, J. A. and Van Dyne, L. (1998). 'Predicting voice behavior in work groups'. Journal of Applied Psychology, 83, 853-68.

Levenson, H. (1974). 'Activism and powerful others: distinctions within the concept of internalexternal control'. Journal of Personality Assessment, $38,377-83$. 
McAllister, D. J. (1995). 'Affect- and cognition-based trust as foundations for interpersonal cooperation in organizations'. Academy of Management Journal, 38, 24-59.

Mehra, A., Kilduff, M. and Brass, D. J. (2001). 'The social networks of high and low self-monitors: implications for workplace performance'. Administrative Science Quarterly, 46, 121-46.

Miceli, M. P. and Near, J. P. (1985). 'Characteristics of organizational climate and perceived wrongdoing associated with whistle-blowing decisions'. Personnel Psychology, 38, 525-44.

Mitchell, T. R., Smyser, C. M. and Weed, S. E. (1975). 'Locus of control: supervision and work satisfaction'.Academy of Management Journal, 18 , 623-31.

Morrison, E. W. and Milliken, F. J. (2000). 'Organizational silence: a barrier to change and development in a pluralistic world'. Academy of Management Review, 25, 706-25.

Morrison, E. W. and Phelps, C. C. (1999). 'Taking charge at work: extrarole efforts to initiate workplace change'. Academy of Management Journal, 42, 403-19.

Nembhard, I. M., A. C. Edmondson. 2006. Making it safe: The effects of leader inclusiveness and professional status on psychological safety and improvement efforts in health care teams. Journal of Organizational Behavior 27(7): 941-966

Phillips, J. M. and Gully, S. M. (1997). 'Role of goal orientation, ability, need for achievement, and locus of control in the self-efficacy and goal-setting process'. Journal of Applied Psychology, 82, 792-802.

Pierce, J. L., Dunham, R. B. and Cummings, L. L. (1984). 'Sources of environmental structuring and participant responses'. Organizational Behavior and Human Performance, 33, 214-42.
Premeaux, S. F., \& Bedeian, A. G. (2003). "Breaking the Silence: The Moderating Effects of Self Monitoring in Predicting Speaking Up in the Workplace". Journal of Management Studies, 40, 1537-1562

Rotter, J. B. (1992). 'Some comments on the "cognates of personal control".' Applied \& Preventive Psychology, 1, 127-9.

Schilit, W. K. and Locke, E. A. (1982). 'A study of upward influence in organizations'. Administrative Science Quarterly, 27, 304-16.

Scott, S. G. and Bruce, R. A. (1994). 'Determinants of innovative behavior: a path model of individual innovation in the workplace'. Academy of Management Journal, 37, 580-607.

Snyder, M. (1979). 'Self-monitoring processes'. Advances in Experimental Social Psychology, 12, 85-128.

Snyder, M. and Gangestad, S. (1982). 'Choosing social situations: two investigations of selfmonitoring processes'. Journal of Personality and Social Psychology, 43, 123-35.

Van Dyne, L. and LePine, J. A. (1998). 'Helping and voice extra-role behaviors: evidence of construct and predictive validity'. Academy of Management Journal, 41, 108-19.

Van Dyne, L., Cummings, L. L. and Parks, J. M. (1995). 'Extra-role behaviors: in pursuit of construct and definitional clarity (a bridge over muddied waters)'. Research in Organizational Behavior, 17, 215-85.

Watson, D., Suls, J. and Haig, J. (2002). 'Global self-esteem in relation to structural models of personality and affectivity'. Journal of Personality and Social Psychology, 83, 185-97.

Withey, M. J. and Cooper, W. H. (1989). 'Predicting exit, voice, loyalty, and neglect'. Administrative Science Quarterly, 34, 521-39. 